\title{
Problemas de Produto Cartesiano, Raciocínio Combinatório e Intervenção do Professor ${ }^{1}$
}

\author{
Kelly Cristine Placha ${ }^{2}$ \\ Maria Lucia Faria Moro \\ Universidade Federal do Paraná
}

\begin{abstract}
RESUMO - O artigo descreve a natureza das soluções de crianças a problemas de produto cartesiano conforme níveis do raciocínio combinatório ali implicados, para identificar a aprendizagem ocorrente e a natureza das intervenções de ensino. Participaram cinco crianças de nove anos, alunas da $3^{\text {a }}$ série de uma escola municipal de Ensino Fundamental. A coleta de dados foi realizada em duas sessões individuais para solucionar problemas por escrito. A intervenção de ensino da pesquisadora seguiu o estilo clínico-crítico. Da análise qualitativa dos dados gravados em vídeo foram identificados os seguintes níveis de solução: resposta contextualizada sem indício de combinação, primeiras aproximações à solução combinatória, obtenção de algumas combinações e presença de solução combinatória. As formas identificadas de intervenção do adulto foram: orientadora, reorientadora, questionadora e instigadora. A discussão sublinha a relação das intervenções de ensino descritas na ocorrência dos progressos pontuais das crianças em direção a soluções de caráter combinatório.
\end{abstract}

Palavras-chave: produto cartesiano; raciocínio combinatório; aprendizagem matemática; intervenção do professor.

\section{Problems of Cartesian Product, Combinatory Reasoning, and Teacher's Intervention}

\begin{abstract}
This paper describes the nature of children's solutions to Cartesian product problems according to their implied levels of combinatory reasoning in order to identify the learning process going on therein, and the nature of teaching intervention. Five nine-year-old students enrolled at the $3^{\text {rd }}$ grade of a state elementary school were the participants. Data were collected during two individual sessions of problem solving. The researcher's teaching intervention was on the clinical-critical format. The qualitative analysis of videotape data resulted in the identification of the following solution levels: contextualized answer without signs of combination, the first approaches to combinatory solutions, the arising of some combinations, and the presence of combinatory solutions. The identified forms of teaching interventions were: orienting, re-orienting, questioning, and instigating. The discussion underlies the relevance of the described teaching interventions to the punctual progress of each child towards solutions with combinatory marks.
\end{abstract}

Keywords: Cartesian product; combinatory reasoning; mathematical learning; teacher's interventions.

As últimas décadas têm sido marcadas por uma grande variedade de pesquisas na área da educação matemática. Muitas dessas pesquisas tratam da elaboração de crianças, adolescentes, adultos e professores, de diversos conceitos matemáticos presentes nos currículos escolares (e.g., Carraher, Carraher \& Schliemann, 1989; Kamii, 2005; Nunes \& Bryant, 1997; Vergnaud, 1983, 1991).

Em muitas dessas pesquisas percebe-se forte influência da epistemologia genética, teoria para a qual a aprendizagem só é possível quando há assimilação ativa por parte do sujeito que aprende (Piaget, 1973b). Um dos pontos que merece destaque nesse quadro é a preocupação dos pesquisadores em conhecer, compreender e explicar o caráter ativo da aprendizagem de conteúdos matemáticos escolares, indi-

1 Este artigo foi escrito com base na pesquisa realizada pela primeira autora para sua Dissertação de Mestrado em Educação, defendida no Programa de Pós-Graduação em Educação do Setor de Educação da Universidade Federal do Paraná, linha de pesquisa Educação Matemática, sob a orientação da segunda autora

2 Endereço: Rua Nicolau José Gravina, 1801, Santa Felicidade. Curitiba, PR. CEP 82010-020. Fone: (41) 3319-2490. E-mail: kellyplacha@ hotmail.com. cando a necessidade de uma aprendizagem matemática com compreensão dos conceitos.

Outro ponto a destacar nessas pesquisas refere-se ao que Piaget (1973b) já assinalava como o principal problema do ensino da Matemática: o ajuste entre as estruturas inteligentes da criança e o método utilizado pelo professor para o ensino dos conceitos. Conforme essa posição, é indispensável a intervenção do professor para, em sala de aula, levar os alunos à reflexão e à descoberta de noções, relações e propriedades matemáticas, fazendo-os, assim, evoluir sua compreensão dos conceitos trabalhados.

Pesquisas têm descrito uma real construção de conceitos em sala de aula quando o professor permite e incentiva as crianças a elaborar e utilizar estratégias próprias de cálculo na solução de problemas (Brito, 2001; Franchi, 1999; Kamii, 2005; Nunes \& Bryant, 1997; Sinclair, 1990). Conforme Sinclair (1990), estratégias próprias de cálculo são os procedimentos originais, não canônicos, de cálculo mental, oral e escrito, elaborados pelas crianças na solução de problemas, perspectiva adotada neste estudo.

Nessa mesma linha, o papel do professor não mais se restringe evidentemente a transmitir conhecimentos pron- 
tos, mas, sobretudo, é o de provocar ou instigar as crianças a elaborar estratégias próprias de cálculo, para que façam sua construção conceitual. Piaget (1973b) já recomendava a necessidade de uma intervenção instigante do adulto para a elaboração espontânea da criança, em vez de lhe impor uma elaboração formalizada e pronta.

Um último ponto a destacar das indicações das referidas pesquisas é a importância atribuída aos conhecimentos e às experiências prévias das crianças. Starepravo (1997) pontua que a ação mental é empobrecida quando as crianças recebem informações prontas e, em seguida, aplicam essas informações em exercícios escolares; a ação mental só ocorre quando a criança coloca o novo em relação com aquilo que já conhece e vivenciou.

Papert (1994) sublinha que a aprendizagem significativa ocorre a partir da solução de problemas e do estabelecimento de relações com as experiências vividas. $\mathrm{O}$ autor ressalta que os conhecimentos que as crianças têm devem conectar-se aos problemas propostos em sala de aula; caso contrário, a aprendizagem não será significativa.

O presente estudo adota os seguintes pressupostos: (1) a construção dos conceitos matemáticos só ocorre quando há ação mental de parte do sujeito que aprende; (2) o trabalho com solução de problemas leva o aluno a pensar, elaborar hipóteses e operar com os dados apresentados, estabelecendo relações com outras experiências já vivenciadas; (3) é necessário não só permitir, mas também incentivar a elaboração e o emprego pelo aluno de suas estratégias próprias de solução. As características principais deste estudo são as de, empírica e qualitativamente, descrever as soluções sequenciais dos participantes a problemas multiplicativos de produto cartesiano (ou produto de medidas, conforme Vergnaud, 1991) em sua relação com as formas de intervenção de ensino do adulto ali ocorrente, para verificar as alterações dessas soluções em termos do raciocínio combinatório nelas implicado.

Com relação ao processo do ensino e da aprendizagem da matemática, a literatura já oferece resultados relevantes sobre a compreensão das estruturas multiplicativas (e.g., Barreto, 2001; Broitman, 2000; Bryant \& Kornilaki, 1999; Hino, 2000; Park \& Nunes, 2001; Spinillo, 1995). Contudo, ela não os tem ainda tão evidentes no que concerne à construção de conceitos e relações multiplicativas em problemas de produto cartesiano. A maioria dos estudos aborda multiplicações de isomorfismo de medidas (Franchi, 1999; Starepravo, 2001). Eis uma das razões, então, para realizar um estudo sobre as soluções das crianças a problemas multiplicativos de produto cartesiano.

Embora pouco numerosos, os estudos sobre multiplicações de produto cartesiano abordam, em geral: (a) a solução de problemas, por crianças pequenas, em situações de combinação de materiais concretos, com destaque à possibilidade de incentivar o raciocínio combinatório (English, 1992); (b) a compreensão que o professor tem desse conceito (Moro \& Soares, 2006a); e (c) a análise do processo ensinoaprendizagem desse conceito em sala de aula (Costa, 2003; Esteves, 2001; Taxa, 2001; Vergnaud, 1983).

Vergnaud $(1983,1991)$ chama os referidos problemas de 'produto de medidas', pertencentes que são ao campo conceitual das estruturas multiplicativas. Defende que a compreensão desse tipo de problema é condição para o entendimento de outros conceitos também pertencentes àquele campo. O não-entendimento dos conceitos e relações ali presentes traria às crianças dificuldades que iriam além do domínio de multiplicações ou divisões, das quais, para o autor, um exemplo é o da progressão do raciocínio combinatório. Taxa (2001) apresenta evidências para sustentar que a compreensão dos problemas de estrutura multiplicativa de produto de medidas pode ocorrer na escola, desde o início do Ensino Fundamental.

Mesmo constando em documentos oficiais referentes às séries inicias do Ensino Fundamental (Brasil-Ministério da Educação, 2001; Estado do Paraná - Secretaria de Estado da Educação, 2002), problemas de produto de medidas não são frequentes entre os que as crianças solucionam em sala de aula, embora impliquem o raciocínio combinatório, fundamental na matemática, aplicável também na solução de problemas de outras áreas. Os Parâmetros Curriculares Nacionais (PCN) destacam, para o ensino da Matemática, quatro grupos de situações relacionadas às estruturas multiplicativas que necessitam ser exploradas nas séries iniciais do Ensino Fundamental. Entre elas aparecem "as situações associadas à ideia de combinatória" (Brasil-Ministério da Educação, 2001, p. 111).

As contribuições recém expostas sinalizam que, para melhor conhecer como ocorre, na aprendizagem escolar, a compreensão das relações multiplicativas de produto cartesiano, deve-se considerar os diversos aspectos ali envolvidos, tais como: o incentivo ao uso pelo aprendiz de estratégias próprias de solução, conforme seus conhecimentos e experiências anteriores, e a necessidade de formas adequadas de intervenção do professor. É relevante ter em conta que a compreensão das referidas relações interliga-se à construção do raciocínio combinatório. Em acordo com Moro e Soares, (2006b), esse é outro motivo para incentivar e apreciar soluções a problemas de produto cartesiano já nas séries iniciais do Ensino Fundamental.

Com base nas razões apontadas, o problema central do estudo assim se anuncia: Como ocorre o processo de aprendizagem de relações multiplicativas de produto de medidas (ou cartesiano) de crianças da $3^{a}$ série, na solução de problemas, sob a intervenção do professor?

Para levar adiante a investigação, foram levantadas duas questões específicas: Como se caracterizam as soluções notacionais e verbais e as interpretações das crianças a respeito quando estas solucionam problemas multiplicativos de produto de medidas, quanto à presença ou não de raciocínio combinatório? Que formas assumem as intervenções da pesquisadora, no papel de professora, durante as soluções das crianças?

As soluções notacionais e verbais das crianças e suas interpretações sobre essas soluções foram vistas como expressão do processo de aprendizagem em curso. Tais manifestações serviram de referência para as intervenções da pesquisadora, no papel de professora, intervenções estas feitas com o intuito de que as crianças alterassem suas soluções segundo os níveis de raciocínio combinatório ali expressos.

A análise das soluções das crianças é feita, neste estudo, integrada à análise das formas de intervenção da pesquisadora, no papel de professora. Cumprindo esse papel, a pesquisadora propôs e orientou a solução dos problemas, partindo sempre do conhecimento prévio da criança empregado para resolver cada um dos problemas. 
Dessa forma, a progressão (ou não) das soluções das crianças aos problemas propostos foi vista como indicação do processo de aprendizagem de cada uma delas, identificado e traduzido em níveis de construção do raciocínio combinatório, de acordo com os níveis de raciocínio combinatório, descritos por Moro e Soares (2006b).

\section{Método}

\section{Participantes}

Cinco crianças, da faixa etária de nove anos, matriculadas em uma escola municipal de grande área metropolitana, participaram da pesquisa: uma menina e quatro meninos, sorteados aleatoriamente, entre as crianças de cinco das seis turmas de $3^{\text {a }}$ série da escola, do turno da manhã e da tarde. Elas concordaram em participar do estudo e foram previamente autorizadas por seus pais ou responsáveis.

\section{Instrumento e procedimento}

Para realizar o estudo, foram selecionados oito problemas de produto de medidas envolvendo multiplicação em que, com o valor das medidas elementares, a criança deveria encontrar o valor do produto daquelas medidas dadas, combinando duas ou mais medidas elementares. Considerou-se que, ao final da $3^{\text {a }}$ série, soluções via multiplicação seriam menos complexas do que aquelas com divisão para as crianças e estas estariam familiarizadas com o algoritmo da multiplicação, aspectos que as levariam a tentar solucionar os problemas.

Os oito problemas foram apresentados pela pesquisadora (no papel de professora) aos participantes, no formato escrito, um em cada folha de papel sulfite, em duas sessões fora das atividades cotidianas de sala de aula.

A pesquisadora propôs quatro problemas diferentes por sessão, conforme os seguintes tipos: com duas variáveis e valores baixos que apareciam escritos por extenso, sem e com valores distractores ${ }^{3}$; com duas variáveis, mas com valores altos que apareciam numericamente; com três variáveis e valores baixos que apareciam por extenso. Eis os oito problemas:

- Problema 1. Uma panificadora prepara bolos deliciosos. Os bolos podem ser de 3 tamanhos (pequeno, médio e grande) e os sabores podem ser de 6 tipos diferentes (morango, chocolate, brigadeiro, coco, doce de leite e banana). Quantos tipos diferentes de bolo você pode escolher para comprar, combinando um tamanho com um só sabor?

- Problema 2. Em uma loja de carros tem 5 Gols, 5 Palios e 4 Corsas. Ao comprar o carro você pode escolher 2 tipos de rodas: esportiva ou comum. De quantas maneiras diferentes os tipos de carros e rodas podem ser combinados?

- Problema 3. Eduarda tem uma máquina de bordar. Ela borda personagens infantis em camisetas. Eduarda tem 15

3 Valores distractores são os que, desnecessários para a solução, aparecem no texto do problema, para verificar se os sujeitos identificam os valores das variáveis propriamente ditos ou não (Vergnaud, 1983; 1991). cores diferentes de camisetas e 12 personagens diferentes. Quantos tipos diferentes de camiseta ela pode bordar?

- Problemas 4. Em uma sorveteria por quilo existem 7 sabores de sorvete, 3 tipos de coberturas e 2 tipos de casquinha. De quantas maneiras diferentes você pode se servir, sabendo que todos os sorvetes são acompanhados de cobertura e casquinha?

- Problema 5. Uma papelaria vende mochilas de 2 tamanhos (pequena e grande) e em 5 cores diferentes (verde, azul, vermelha, amarela e preta). Amanda quer comprar uma mochila nesta papelaria. Quantos tipos diferentes de mochila ela pode escolher para comprar, combinando uma cor e um tamanho?

- Problema 6. Em uma pizzaria tem 30 sabores e 3 tamanhos diferentes de pizza. A pizza pequena pode ser cortada em 6 fatias, a pizza média pode ser cortada em 8 fatias e a pizza grande pode ser cortada em 12 fatias. De quantas maneiras diferentes os sabores e os tamanhos da pizza podem ser combinados?

- Problema 7. Pedro tem 18 camisetas e 11 bermudas. De quantas maneiras diferentes ele pode se vestir?

- Problema 8. Vou dar uma festa de aniversário e servirei sanduíches. Para fazer os sanduíches comprei 2 tipos de queijo, 3 tipos de patê e 4 tipos de pães. Quantos tipos diferentes de sanduíches podem ser servidos, sabendo que todos vêm acompanhados de um tipo de pão, um tipo de queijo e um tipo de patê?

Para solucioná-los, as crianças foram instigadas a utilizar soluções notacionais e verbais. Quando cada criança finalizava suas notações, recebia o pedido da pesquisadora para explicar os procedimentos e interpretar as notações utilizadas. Os pedidos por explicações seguiram o estilo clínico-crítico proposto por Piaget (1973a). Tal como conhecida, essa forma de interrogar o indivíduo envolve perguntas para obter respostas e justificativas próprias ("Por que você fez assim?"; "Como você pensou?"; "Não dá para fazer de outro jeito?") ${ }^{4}$.

Durante a solução dos problemas, foram dadas às crianças: uma folha de sulfite A4, para cada um dos problemas, uma caneta esferográfica preta e seis canetinhas hidrográficas coloridas, para que pudessem marcar suas respostas.

\section{Análise de dados}

As sessões foram filmadas em vídeo, na íntegra, e os dados (ações, verbalizações, soluções notacionais) foram transcritos em protocolos, de forma livre, compondo-se um protocolo para cada criança, com falas da pesquisadora, e falas, gestos e movimentos da criança. Após a transcrição completa e revisada desses dados, foram eles analisados qualitativamente para que fossem identificadas e descritas as soluções de cada criança e suas alterações, e as formas das intervenções de ensino da pesquisadora a cada sessão.

4 A recordar que o interrogatório clínico-crítico empregado por Piaget para coletar dados visava obter dos sujeitos suas formas próprias de solucionar as tarefas, de pensar e argumentar, pautando-se por fazê-lo falar e, ao mesmo tempo, deixá-lo falar (Piaget, 1973a). 
A análise qualitativa das soluções notacionais e verbais e das interpretações das crianças foi feita com referência aos níveis e subníveis de raciocínio combinatório, descritos por Moro e Soares (2006b), para soluções escritas a problemas de produto de medidas multiplicativos, ali definidos segundo três eixos de referência, a saber: pertinência à pergunta do problema; presença de um ou mais casos de combinação de valores das variáveis; presença de cálculo relacional aditivo e/ou multiplicativo.

\section{Resultados}

No que segue serão expostos primeiro os resultados da análise das soluções dos participantes aos problemas conforme os níveis e/ou subníveis de raciocínio combinatório nelas implicados. Depois, serão descritas as formas de intervenção de ensino do adulto quando é analisada sua relação com as alterações em níveis e subníveis das soluções ao longo e entre sessões.

Os resultados apontaram soluções correspondentes aos níveis de raciocínio combinatório identificados por Moro e Soares (2006b). Porém, foram identificadas soluções de dois diferentes subníveis de raciocínio combinatório, não descritos naquele estudo: IIIA - Os casos favoritos combinando duas variáveis com uma e IIIE - As combinações possíveis entre duas das três variáveis. De outra parte, não foram encontradas soluções de Nível 0: De resposta alheia ao contexto, e soluções dos subníveis IC - Das composições numéricas em diferentes formas de cálculos e IIB - Dos casos favoritos conforme distractor ou variável estranha.

Eis os níveis e subníveis de raciocínio combinatório, identificados neste estudo, analisadas as soluções de todos os participantes aos oito problemas.

\section{Nível I: De resposta contextualizada sem indício de combinação das variáveis.}

Subnível IA: Da escolha de variáveis, que consiste de soluções que contêm escolhas relativas a uma ou mais variáveis, sem qualquer combinação entre elas. Vão desde escolha(s) qual(is)quer relativa(s) a uma variável até escolhas mais organizadas referentes a exemplares diferentes das variáveis e que se reportam a valores diferentes das variáveis. Por exemplo, EDU (Problema 1):

$\mathrm{EXP}^{5}$ - Juntando tudo isso, quantos tipos diferentes de bolo você pode comprar? (Olha para EDU) Quantos tipos diferentes de bolo você pode escolher para comprar, combinando um tamanho com um só sabor?

EDU - (Olha para suas notações, para e olha para a EXP) Três. Será que é três? (Olha para a EXP, fica por algum tempo em silêncio e sorri)

5 A abreviatura EXP indica as intervenções da experimentadora, no papel de professora, durante a solução dos problemas pelas crianças. As outras abreviaturas identificam cada participante.
Subnível IB: Da adição de valores, que consiste de soluções que se limitam ao cálculo aditivo ou à divisão (mental ou não) de parte de todos os valores envolvidos, em certo momento incluindo distractores e não-distractores e, depois, somente os valores das variáveis, conforme sua ordem de aparecimento ou não. Por exemplo, PED (Problema 7) registra no formato de conta escolar de adição 15 (valor para as camisetas) e 12 (valor para os personagens) e total 27.

$\mathrm{EXP}$ - Então aqui você acha que se ela tem 15 cores diferentes de camisetas (Aponta para esta informação no problema) e 12 personagens diferentes (Aponta para esta informação no problema), ela pode bordar quantos tipos diferentes de camiseta? (Aponta para a pergunta do problema)

PED - Vinte e sete. (Olha para a EXP e movimenta a caneta preta na mão)

\section{Nível II: Das primeiras aproximações à solução combinatória}

Subnível IIA: Do caso favorito, que trata da representação de uma e somente uma possibilidade de combinação entre as variáveis (um e somente um valor de cada uma delas). Seria a combinação escolhida por razão estética ou de adequação de uso, às vezes indicados. Quando presentes, os valores distractores são também, às vezes, considerados. Por exemplo, REN (Problema 1) escreve: pequeno chocolate.

Subnivel IIB: Dos casos favoritos, ignorados os distractores, que consiste de soluções que representam alguns casos (sobretudo, três) de combinação das variáveis, cujos valores aparecem emparelhados, sem que os valores distractores interfiram na solução. Os valores das variáveis se excluem: a cada valor de uma variável corresponde somente um valor da outra, por vezes ainda conforme o critério de uso adequado. Há forte marca do esquema de correspondência termo a termo como organizador. Por exemplo, EDU (Problema 2), conforme mostrado na Figura 1.

\section{Nível III: Da obtenção de algumas combinações}

Subnível IIIA: Dos casos favoritos, combinando duas variáveis com uma, que consistem de soluções em que valores das duas variáveis estão presentes, de modo que a cada valor de uma variável correspondem dois valores da outra variável. Essas combinações são obtidas por meio de registro pictórico, escrita alfabética e numérica ou pela combinação dessas formas. Por exemplo, EDU (Problema 1), de acordo com a ilustração da Figura 2:

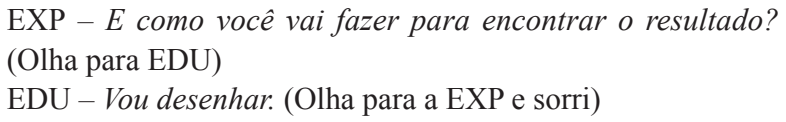

Subnível IIIB: Das buscas iniciais de combinações, "distorcidas" pelo valor de uma variável, que são soluções em que as combinações são representadas de acordo com alguma variável, de maior e/ou de menor valor. Essas com- 


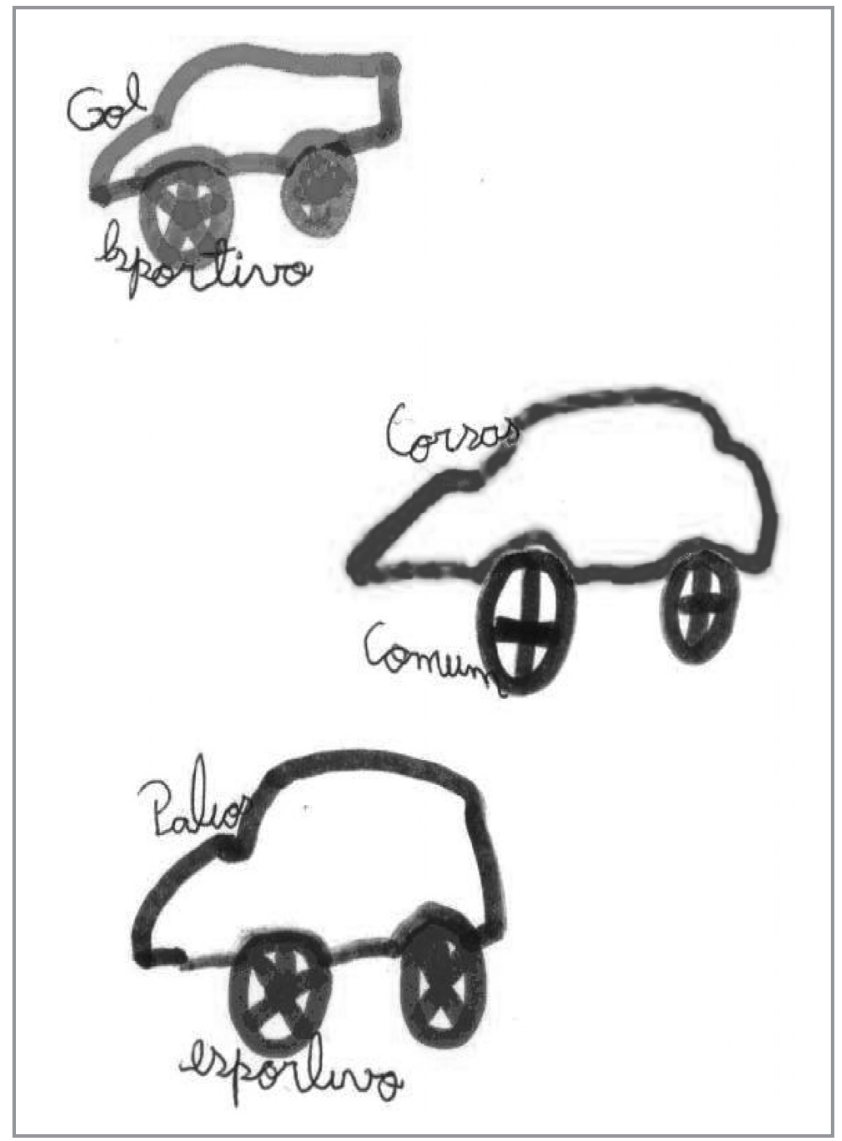

Figura 1. Para cada carro... um tipo de roda.

binações são obtidas por meio de representação pictórica, margeada sempre pela variável de maior valor, na aparente busca de "muitas maneiras". Por exemplo, EDU (Problema 7) desenha 15 camisetas, cada uma com uma cor e um personagem diferente:
$\mathrm{EXP}$ - O que vocêfez aí, você pode me explicar? (Aponta para as notações de EDU)

EDU - Eu fiz as camisetas... E desenhei os personagens. (Olha para suas notações) Quinze camisetas e os 15 personagens. (Olha para a EXP e sorri)

Subnível IIIC: Das aproximações aditivas, multiplicativas e por divisão, que consistem em soluções obtidas mediante diferentes combinações e junções de cálculos aditivos, multiplicativos e de divisão entre alguns e/ou todos os valores das variáveis envolvidas, repetidos ou não, bem como entre resultados desses cálculos, complementados por vezes por valores unitários do texto do problema e em ordens variadas. Por exemplo, MAT (Problema 4):

MAT - (Lê trechos do problema para buscar esta informação) Cobertura é três tipos... (Olha para a EXP e, em seguida, olha para cima) Dá para combinar com... Com os sorvetes. (Olha para a EXP) Com as casquinhas... (Olha para a EXP)

EXP - E quanto que dá no total? (Aponta para o problema) De quantas maneiras diferentes você pode se servir? (Olha para MAT)

MAT - (Olha para cima) Quatorze. (Faz uma pausa e corrige sua resposta) Não!... Colocando mais as três coberturas... Dezessete.

EXP - Você pode me mostrar como é isso que você pensou? (Aponta para a folha de sulfite)

MAT - Tem 14 e dai eu coloquei os três tipos de cobertura. (As mãos continuam embaixo da mesa e ele movimenta o corpo, balançando-o) Daí... Fica 17. (Olha para a EXP)

Subnível IIID: Das muitas combinações aditivo-multiplicativas, que são soluções para problemas com três variáveis, consistindo em número limitado de combinações entre os valores envolvidos, obtidos de adições e multiplicações. São diferentes "junções" aditivo-multiplicativas na busca da resposta em termos de "muitos casos". Por exemplo, BAR (Problema 8):

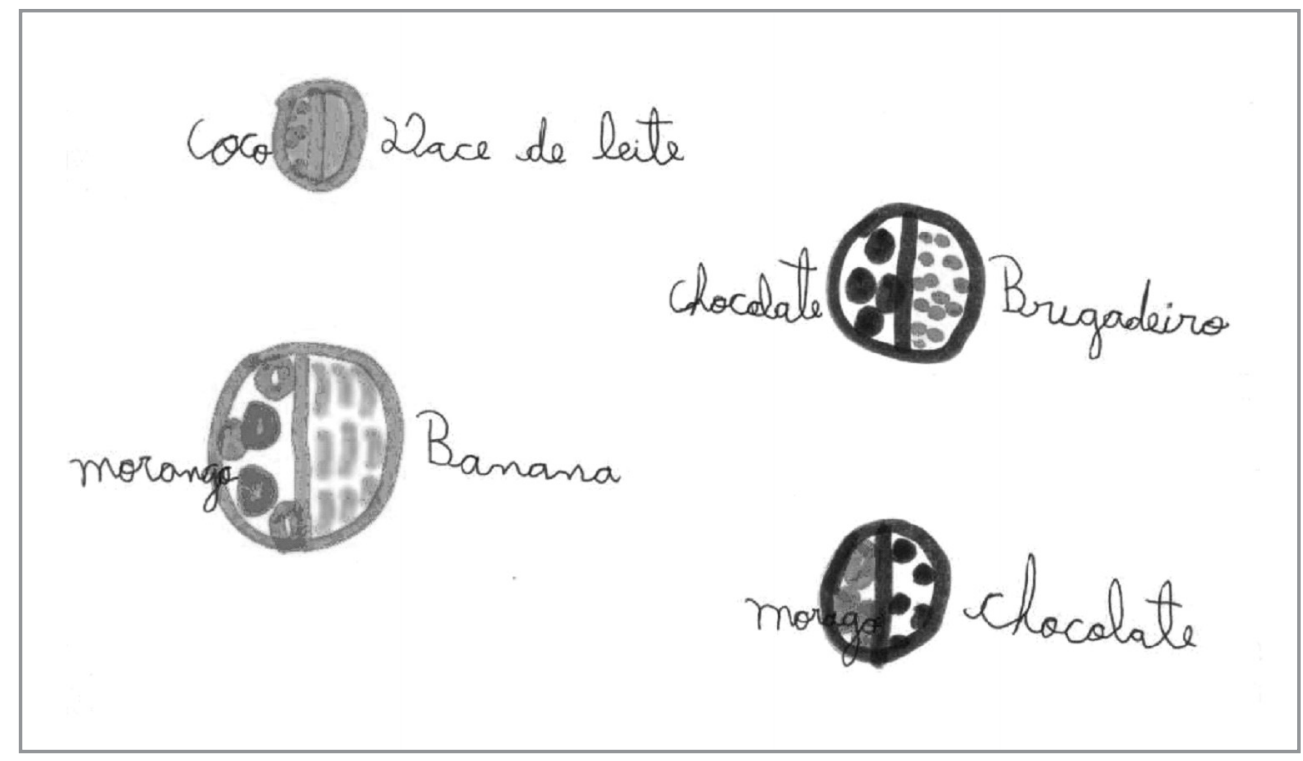

Figura 2. Dois sabores diferentes em cada tamanho de bolo. 


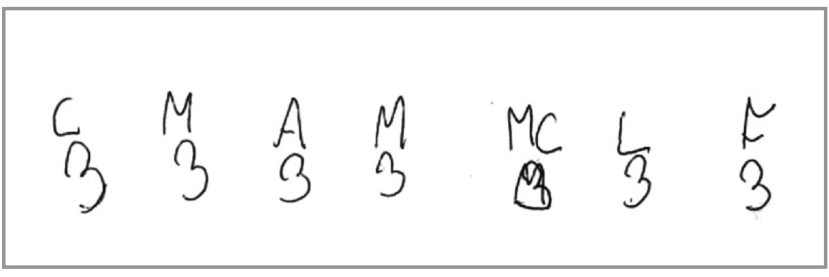

Figura 3. Sabores de sorvete combinados com as coberturas.

BAR - (Escreve) 20 pães.

EXP - Esses 20 seriam o que? (Aponta para o número vinte, escrito por BAR)

BAR - Seriam com... Com os pães com o queijo e o patê. (Movimenta a caneta preta com a mão direita enquanto responde) Vinte e oito, juntando tudo. (Aponta com a caneta preta para sua notação)

EXP - Juntando o quê?

$\mathrm{BAR}$ - Os pães, os queijos e o patê. (Olha para a sua notação e movimenta a caneta preta com a mão direita)

EXP - Por que daria 28? (Coloca a mão esquerda no rosto)

BAR - (Movimenta no ar os dedos das duas mãos) Porque juntando tudo. (Olha para a EXP)

EXP - Juntando tudo o quê? (Olha para BAR)

$\mathrm{BAR}$ - Os queijos, os pães e o patê. (Olha para a EXP)

Subnivel IIIE: Das combinações possíveis entre duas das três variáveis, na solução de problemas com três variáveis. Estão presentes todos os casos possíveis de combinação entre os valores de apenas uma variável de cada vez com apenas os valores de somente uma das outras (por meio de representação pictórica, cálculo aditivo ou multiplicativo convencional, ou por duas ou mais dessas formas de registro) na busca da resposta em termos de "muitos casos". Por exemplo, MAT (Problema 4), conforme apresentado na Figura 3:

EXP - Você pode me explicar o que você fez? (Olha para MAT)

MAT - (Passa a mão no rosto, olha para o lado, movimenta-se na cadeira) Vinte e um. Os... É dos sabores e das coberturas... (Olha para a EXP)

EXP - Vinte e um? Como que você pensou? (Olha para MAT)
MAT - Contando de três em três. (Aponta para os números três de sua notação)

EXP - Me explique. (Aponta para a notação de MAT)

MAT - (Com o dedo indicador da mão esquerda aponta para os números três) Três mais três (Aponta para o primeiro e para o segundo três que escreveu) é seis, com mais três (Aponta para o terceiro três que escreveu) é nove, com mais três (Aponta para o quarto três que escreveu) é 12, (Faz uma pausa e respira fundo) com mais três (Aponta para o quinto três que escreveu) é 15, com mais três (Aponta para o sexto três que escreveu) é dezoito 18 e com mais três (Aponta para o último três que escreveu) dá 21. (Olha para a EXP)

A lembrar que soluções IIIA e IIIE não foram identificadas por Moro e Soares (2006b), do que resultou uma reordenação, neste estudo, dos subníveis do nível III.

\section{Nível IV: Da presença de solução combinatória}

Consiste de soluções em que estão presentes todos os casos possíveis de combinação entre os valores das variáveis (representação pictórica, cálculo aditivo e/ou multiplicativo, "árvore" de possibilidades ou duas ou mais dessas formas de registro, envolvendo ou não escrita alfabética e numérica). Por exemplo, MAT (Problema 1), de acordo com a Figura 4:

EXP - Por que deu 18? (Aponta para a notação de MAT)

MAT - (Olha para sua notação) Três mais três dá seis... Daí com mais três... (Faz uma pausa) Daí ia dar... (Faz uma pausa) Nove... Daí com mais três, 12... Com mais seis, dai 18. (Olha para a EXP)

EXP - Então você juntou... O que você combinou para dar $18 ?$ (Olha para MAT) Combinou o que com o que?

MAT - O número três. (Continua enrolando a ponta do cabelo coma mão esquerda)

EXP - Tá! Mas esses três são do que? (Aponta para os números três escritos por MAT)

MAT - Três tamanhos... (Olha para a EXP)

EXP - Três tamanhos e seis o quê?

MAT - Tipos de bolo. (Olha para a EXP)

EXP - Tipos de bolo?

MAT - Não, sabores. (Olha para a EXP e sorri)

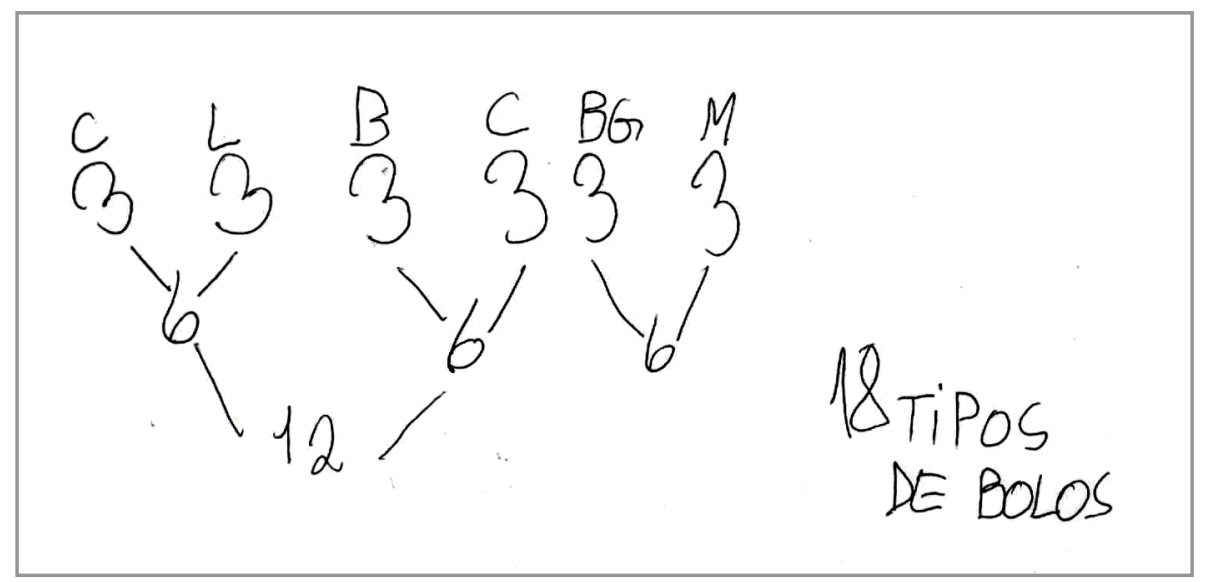

Figura 4. Árvore de possibilidades: sabores e tamanhos de bolo. 
Para responder à questão sobre as formas de intervenção do adulto, foram identificadas as formas de intervenção orientadora, reorientadora, questionadora e instigadora, descritas como segue:

- Orientadora: esta forma de intervenção se fez presente no início de cada uma das sessões de solução de problemas. Consistiu em ações de apresentação da tarefa ao participante com explicações sobre a natureza dessa tarefa e os diversos procedimentos e materiais passíveis de uso, e de recomendações sobre a necessidade do registro das soluções. Essa forma de intervenção também apareceu no início da solução de cada problema, com eventual leitura do mesmo. Além disso, no decorrer da solução de cada um dos problemas, ela também apareceu, embora com menor frequência. Por exemplo, o pesquisador iniciava a tarefa de solução de problema, apresentando e explicando a atividade que seria desenvolvida, entregava os materiais a serem utilizados para o registro da solução encontrada e lia o problema em voz alta a pedido do participante.

- Reorientadora: esta forma de intervenção se fez presente no decorrer de cada uma das sessões de solução de problemas. Consistiu em indicações para relembrar ao participante a atividade que estava sendo executada, a diversidade de notações e de materiais que poderia utilizar, para reencaminhá-lo na busca de uma solução e/ou relembrá-lo das recomendações iniciais. Por exemplo:

EXP - Então vamos ver lá. (Aponta com a caneta preta para a pergunta do problema) Quantos tipos diferentes de bolo você pode escolher para comprar, combinando um tamanho com um só sabor? (Olha para MAT)

MAT - (Com a mão esquerda enrola a ponta do cabelo)

EXP - Então lá tem vários bolos... Quantos bolos diferentes será que têm nessa panificadora?

MAT - (Enquanto a EXP fala, com a mão esquerda mexe no queixo) Vários. (Olha para o problema)

EXP - Como que vai dar para descobrir sabe... Com estas informações que este problema está dando? (Aponta para o problema)

MAT - Chocolate pode ir com o grande. (Olha para a EXP)

- Questionadora: esta forma se fez presente no decorrer e ao término de cada solução notacional e/ou verbal, bem como ao término das interpretações sobre as soluções apresentadas pelo participante. Com essa forma, objetivou-se colocar perguntas para que o participante refletisse sobre a solução notacional que produzira e/ou sobre o conteúdo da verbalização que expressara. Conforme o esperado, esse tipo de intervenção suscitou outras de mesmo tipo, de acordo com as respostas dos participantes. Essas perguntas possibilitaram à pesquisadora captar mais elementos sobre a compreensão da criança para melhor analisar o seu raciocínio. Por exemplo:

EXP - O que o número seis representa? (Aponta com o dedo indicador da mão direita para o número seis)

PED - (Olha para a EXP) Seis sabores.

EXP - E o três? (Olha para PED)

PED - (Olha para a EXP) Tamanho...

$\mathrm{EXP}-$ E o 18 representa o quê?
PED - (Aponta com a caneta para as informações do problema, coloca a mão esquerda no rosto, olha para o problema, pára e coloca a mão na boca) $O$ resultado. (Olha para a EXP)

EXP - Representa o resultado. Mas o resultado é o que? São os tipos diferentes do que?

PED - Do bolo. (Permanece olhando para a EXP e com a mão esquerda na boca)

EXP - São 18 o quê?

PED - Bolos diferentes. (Olha para a EXP)

$\mathrm{EXP}$ - Combinando o que... Os?

PED - Os sabores...

EXP - Com os... (Aponta para as notações de PED)

PED - Tamanhos. (Olha para a EXP e sorri)

- Instigadora: é forma que se fez presente intercalada à forma questionadora durante a solução de todos os problemas. Consistiu de questões que provocaram o participante a iniciar a busca de uma solução notacional e/ou verbal, bem como a refletir sobre parte de sua solução notacional, a buscar outra solução, avaliando-a. Por exemplo:

EXP - Então aqui você utilizou uma continha... (Para a sentença matemática escrita por REN) Que conta é essa? Uma operação do que? (Olha para REN e aponta para sua notação)

REN - (Olha para sua notação) De mais.

EXP - De mais! Será que você já aprendeu na escola uma outra operação que você também conseguisse responder este problema? Que também respondesse este problema? (Aponta para a notação de REN e, em seguida, olha para REN)

REN - (Acena afirmativamente com a cabeça, coloca a mão esquerda na frente da boca e coloca a caneta preta próxima ao rosto)

EXP - Qual? (Aponta para a notação de REN)

REN - De vezes. (Olha para a EXP e sorri)

EXP - Como seria? (Aponta para a notação de REN)

REN - Seis... (Olha para sua notação) Vezes o três. (Olha para a EXP)

EXP - Então anota para a gente pensar junto. (Aponta para a folha de sulfite)

REN - (A mão esquerda apoia a folha de sulfite e com a caneta preta "arma" o algoritmo convencional da multiplicação: 6 × 3 =18) Dezoito. (Olha para a EXP)

Foram observados sinais de relação entre níveis e subníveis de soluções (a cada tipo de problema) e suas alterações (nas duas sessões) e as formas de intervenção da experimentadora, no papel de professora. Assim sendo:

- na solução aos Problemas 1 e 5 (duas variáveis, valores baixos e sem a presença dos valores distractores) predominaram avanços de níveis anteriores para o nível IV, com alternância das formas de intervenção da experimentadora, destacando-se as formas orientadora e reorientadora. No decorrer da solução dos Problemas 2 e 6 (duas variáveis, valores baixos e presença dos valores distractores) predominaram avanços de níveis menos adiantados para solução de nível IV, sobretudo na segunda sessão, e destacaram-se as formas de intervenção questionadora e instigadora.

- na solução aos Problemas 3 e 7 (duas variáveis e valores altos) predominou a manutenção de solução de nível $\mathrm{IV}$, na primeira tentativa. Apareceram todas as formas de 
intervenção da experimentadora, sobretudo a questionadora e a instigadora.

- na solução aos Problemas 4 e 8 (três variáveis e valores baixos) predominaram avanços na primeira sessão, mas não para solução de nível IV. Na segunda sessão predominaram avanços de nível menos adiantado para o nível IV. Houve alternância das formas de intervenção, com predominância da forma questionadora.

Esses resultados possibilitaram identificar mudanças dos níveis menos avançados para os mais avançados de solução, no decorrer das sessões, para todos os participantes. E, ao que tudo indica, esses avanços de nível podem ter relação com as formas de intervenção da pesquisadora, no papel de professora.

\section{Discussão}

Conforme anunciado, este estudo analisou o processo de aprendizagem de relações multiplicativas de produto de medidas de crianças de $3^{\text {a }}$ série do Ensino Fundamental, na solução de problemas, sob a intervenção do professor.

Um primeiro ponto a destacar é o seguinte: terem sido identificadas soluções de mesmo nível e de nível diferente de raciocínio combinatório daqueles descritos por Moro e Soares (2006b), ao mesmo tempo em que vai ao encontro do proposto por essas autoras, também acrescenta novos subníveis à hierarquia por elas descrita. A sublinhar que Moro e Soares propuseram a referida hierarquia analisando somente soluções notacionais, enquanto, nesta pesquisa, foram analisadas também soluções verbais das crianças e suas interpretações sobre as notações produzidas. Essa análise mais ampla não só possibilitou melhor compreender e ativar a aprendizagem das crianças mediante uma efetiva e pontual intervenção da pesquisadora, no papel de professora, como ocasionou a identificação de níveis diferentes de raciocínio combinatório expressos nas soluções. Logo, pode-se descrever a progressão do raciocínio combinatório pelo exame de soluções a problemas de produto de medida.

A análise do conjunto das realizações de cada criança mostrou que, do ponto de vista da ausência ou presença do raciocínio combinatório, houve mudanças de níveis menos avançados para níveis mais avançados de solução, para todas as crianças, o que significa ter havido aprendizagem.

Porém, na primeira sessão, essa aprendizagem foi menos estável: na maior parte dos casos, as crianças partiram de solução de nível menos adiantado para solução de nível mais adiantado, mas alternando soluções desses níveis. Já na segunda sessão houve aprendizagem mais estável, pois predominou a manutenção de solução de nível IV desde a primeira tentativa ou o avanço consistente de solução de nível menos adiantado para solução de nível mais adiantado.

Quanto à natureza das formas de intervenção da pesquisadora, no papel de professora, o predomínio das formas de intervenção orientadora e reorientadora no início das sessões (Problemas 1 e 5, respectivamente) pode ser explicado pela necessidade de apresentar às crianças a tarefa, explicitar a importância do registro das soluções, os diversos procedimentos de cálculo e os materiais para uso. Também, quando solicitada, a pesquisadora leu os problemas, relembrando as recomendações iniciais sempre que necessário. Por tais razões é que, durante a solução de todo os problemas, houve orientação e reorientação, mas com menor intensidade, como também, à medida que as crianças familiarizam-se com a tarefa, tais formas de intervenção deram lugar às formas questionadora e instigadora.

A presença da forma questionadora no decorrer e ao término de cada solução notacional e/ou verbal, bem como ao término das interpretações sobre as soluções apresentadas pelas crianças, tem sua explicação porque não só a pesquisadora assim pretendia captar mais elementos sobre a compreensão da criança para melhor analisar suas soluções, como também tinha o objetivo de provocar soluções mais avançadas quanto aos patamares do raciocínio combinatório ali implicado.

Essas mesmas razões podem explicar porque a forma de intervenção instigadora apareceu sempre intercalada à forma questionadora durante a solução de todos os problemas, para levar a criança a refletir sobre suas soluções, avaliá-las, buscar outras. Assim, essa intervenção instigadora aparece ligada aos avanços das soluções de cada criança. Porém, esses avanços devem ser vistos como pontuais e, relativos aos problemas focalizados, sem significar um desenvolvimento pleno do raciocínio combinatório.

Cumpre, porém, sublinhar o emprego alternado das quatro formas de intervenção identificadas, alternância esta ligada aos diversos momentos da tarefa e adaptada ao andamento das soluções, diante do propósito de ativar a compreensão infantil. Ao que tudo indica, essa alternância de formas diversas de intervenção deve ter tido algum papel nos avanços das soluções, aqui vistos como avanços de aprendizagem.

Destacamos que esses avanços de aprendizagem das crianças aparecem também ligados ao tipo de problema. Afinal, os problemas propostos apresentavam diferentes níveis de dificuldade: duas ou três variáveis; valores altos e baixos para as variáveis; presença ou ausência dos valores distractores e tipo de registro dos valores, em algarismos ou escrita alfabética.

Em comparação com a solução das crianças aos outros problemas, apenas nos Problemas 4 e 8 as crianças tiveram avanços menos expressivos, provavelmente porque eles envolviam a presença de três variáveis. A solução desse tipo de problema implica a representação tridimensional, pois a utilização de um diagrama bidimensional, presente no repertório das crianças examinadas, não é suficiente para sua solução.

Foi assim que, na solução do Problema 4, durante a primeira sessão, apenas uma das cinco crianças expressou solução de nível IV. Já as outras três partiram de soluções de níveis I e II para atingir soluções de nível III, e uma apresentou somente solução de nível I. Na solução do Problema 8, já na segunda sessão, quatro das cinco crianças obtiveram solução de nível IV, somente em segunda tentativa, todas elas tendo partido de solução de nível I. Apenas uma das crianças, também partindo de solução de nível I, avançou para solução de nível III.

Os problemas que apresentavam duas variáveis, sobretudo aqueles com valores baixos, então, mais fáceis, possi- 
bilitaram a utilização de uma variedade maior de soluções notacionais pelas crianças: registros pictóricos, cálculos aditivos, cálculos multiplicativos, "árvore" de possibilidades, escrita alfabética e numérica.

Brito, Alves e Neves (2003) argumentam que quando os valores das variáveis são baixos é possível que as crianças elaborem uma representação gráfica que as auxilie na solução do problema. Segundo as autoras, o mesmo não é possível com valores altos, o que passa a exigir a utilização de cálculos formais. Vergnaud (1983), por sua vez, destaca a importância e a necessidade de o professor apresentar aos alunos problemas com valores altos, pois não há como os alunos desenvolverem conceitos complexos se eles não têm contato com situações complexas.

Em consonância com outros estudos (Franchi, 1999; Kamii, 2005; Pavanello, 1994), nossos resultados possibilitaram identificar que, embora as crianças já tivessem aprendido os algoritmos convencionais na escola, só os utilizaram quando provocadas pela pesquisadora. Seu uso inicial de estratégias próprias de cálculo parece ter-lhes sido mais significativo na solução dos problemas propostos. A destacar que as crianças resolveram os problemas fora da sala de aula, em um ambiente diferenciado, o que sugere alguma influência do contexto no emprego de alternativas estratégicas de solução que não as algorítmicas, em geral ainda predominantes nas salas de aula, além de ter ocorrido o incentivo inicial da pesquisadora para tanto.

Com essa apreciação não queremos diminuir o papel nem excluir os algoritmos convencionais do ensino e da aprendizagem matemática. Entendemos, no entanto, que eles devem ser compreendidos e empregados pelas crianças gradativamente, partindo das estratégias de cálculo que lhes sejam significativas, as quais vão permitir-lhes atribuir significado aos algoritmos, percebendo sua eficácia. Piaget (1973b) já defendia que a formalização tem seu momento específico e não pode ser prematura; ao contrário, ela deve aparecer como a finalização de um processo de construção do conceito trabalhado.

Os resultados que obtivemos, embora apenas com cinco crianças, permitiram identificar uma variedade de estratégias próprias de cálculo utilizadas por elas na solução dos problemas propostos. Vimos que essas estratégias permitiram à pesquisadora, no papel de professora, identificar, acompanhar e intervir no processo de aprendizagem dessas crianças em consonância com recomendações da literatura sobre a importância das estratégias próprias de cálculo na compreensão de conceitos matemáticos, tendo como referência inicial os conhecimentos e experiências prévias das crianças e lhes possibilitando participação ativa na sua aprendizagem (Carraher, Carraher \& Schliemann, 1989; Franchi, 1999; Kamii, 2005; Nunes \& Bryant, 1997; Sinclair, 1990).

Uma última indicação vem dos resultados desta pesquisa. Trata-se da relevância de trabalhar os conceitos matemáticos a partir da solução de problemas, conforme a literatura o recomenda, em especial, no caso de problemas de raciocínio combinatório (e.g., English, 1992; Iannece, Nazzaro \& Tortora, 2002; Kishimoto, 2000; Mekhmandarov, 2000; Misailadou \& Williams, 2003; Monteiro, 2003; Moro \& Soares, 2006b; Taxa, 2001). A situação de solução dos pro- blemas, conduzida como o foi, tende a levar as crianças à necessidade de refletir, analisar e elaborar hipóteses com os dados apresentados, estabelecendo relações com os conhecimentos prévios e confrontando ideias para a construção e reconstrução dos conceitos. Então, não se deve esquecer que esse processo foi marcado por um estilo de intervenção do pesquisador, que lhe permitiu, como professor, conhecer e acompanhar o processo de aprendizagem das crianças, propondo intervenções pertinentes e significativas (Vergnaud, 1983; 1991).

\section{Considerações Finais}

Dos resultados relatados, algumas indicações interessantes podem ser feitas aos professores e pesquisadores da área da educação matemática.

A primeira assinala a relevância das estratégias de solução próprias das crianças, em particular suas interpretações a respeito de quando aprendem matemática na escola. Afinal, essas interpretações significam-lhes pensar e refletir sobre o que estão fazendo, um aspecto que merece ser mais bem conhecido. E, ao professor, permite-lhe compreender, acompanhar o processo de aprendizagem e elaborar intervenções pertinentes que atendam às necessidades específicas das crianças, instigando-as à busca de novas estratégias de solução.

A segunda recomendação dá força à ideia de que, nas séries iniciais do Ensino Fundamental, deve-se trabalhar com problemas de produto cartesiano para ativar o raciocínio combinatório e sempre com base no patamar de compreensão em que as crianças se encontram. Segundo a perspectiva adotada no estudo, essa recomendação estende-se ao trabalho com diferentes problemas envolvendo estruturas multiplicativas desde a Educação Infantil, em patamar plausível e em formas adaptadas às peculiaridades dos alunos.

A terceira recomendação sublinha a provável importância e a necessidade de os professores conhecerem o conceito matemático com o qual trabalham, e os patamares de sua construção, para que possam auxiliar seus alunos nessa construção em situações de aprendizagem. Compreender o conceito seria necessário a adequadas formas de intervenção em sala de aula se o propósito é o da compreensão conceitual (Costa, 2003).

Finalmente, aos pesquisadores, nossos resultados pedem que se prossiga a identificação de níveis hierárquicos de elaboração do raciocínio combinatório na compreensão matemática, não apenas examinando-se soluções a problemas de produto cartesiano, e também os de divisão, como também a problemas referentes a outros conceitos e relações da área.

\section{Referências}

Barreto, I. M. A. (2001). Problemas verbais multiplicativos de quarta-proporcional: a diversidade de procedimentos de resolução. Dissertação de Mestrado, Pontifícia Universidade Católica de São Paulo, São Paulo. 
Brasil-Ministério da Educação (2001). Parâmetros Curriculares Nacionais: Matemática ( $3^{\mathrm{a}}$ ed.). Brasília: Ministério da Educação, Secretaria da Educação Fundamental.

Brito, M. R. F. (2001). Psicologia da educação matemática. Florianópolis: Insular.

Brito, M. R. F., Alves, E. V., \& Neves, L. F. (2003). A solução de problemas de estrutura multiplicativa [Resumo]. Em Sociedade Brasileira de Psicologia do Desenvolvimento (Org.), Anais do IX Congresso Brasileiro de Psicologia do Desenvolvimento (p. 105). João Pessoa: SBPD/UFPB.

Broitman, C. (2000). El tratamiento didáctico de problemas multiplicativos desde el inicio de la escolaridad básica. Projeto - Revista de Educação, 2, 38-43.

Bryant, P., \& Kornilaki, E. (1999). Children's development of multiplicative thinking [Resumo]. Em European Society of Developmental Psychology (Org.), I $X^{\mathrm{th}}$ European Conference on Developmental Psychology: Human Development at the Turn of the Century. Abstracts (p. 389). Spetses: ESDP/University of Athens.

Carraher, T, Carraher, D., \& Schliemann, A. (1989). Na vida dez na escola zero ( $\left.3^{\mathrm{a}} \mathrm{ed}\right)$. São Paulo: Cortez.

Costa, C. A. (2003). As concepções dos professores de matemática sobre o uso da modelagem no desenvolvimento do raciocínio combinatório no ensino fundamental. Dissertação de Mestrado, Pontifícia Universidade Católica de São Paulo, São Paulo.

English, L. (1992). Children's use of domain-specific knowledge and domain-general in novel problem solving. British Journal of Educational Psychology, 62, 203-216.

Estado do Paraná-Secretaria de Estado da Educação (2002). Estudos complementares AVA 2000: análise de resolução em questões de matemática. Curitiba: Secretaria de Estado da Educação.

Esteves, I. (2001). Investigando os fatores que influenciam o raciocínio combinatório em adolescentes de 14 anos $-8^{a}$ série do ensino fundamental. Dissertação de Mestrado, Pontifícia Universidade Católica de São Paulo, São Paulo.

Franchi, A. (1999). Considerações sobre a teoria dos campos conceituais. Em S. D. A. Machado(Org.), Educação Matemática: uma introdução (pp. 155-195). São Paulo: EDUC.

Hino, K. (2000). Process of internalizing new use of multiplication through classroom instruction: a case study. Em T. Nakahara \& M. Koyama (Orgs.), Proceedings of the $24^{\text {th }}$ Annual Conference of the PME, Vol. 3 (pp. 49-56). Hiroshima: Hiroshima University.

Iannece, D., Nazzaro, P. E., \& Tortora, R. (2002). From naive drawing to Cartesian representation. Em A. D. Cockburn \& E. Nardi (Orgs.), Proceedings of the $26^{\text {th }}$ Annual Conference of the PME, Vol. 1 (p. 323). Norwich, UK: UEA/PME.

Kamii, C. (2005). Crianças pequenas continuam reinventando a aritmética (séries iniciais). Implicações da teoria de Piaget ( $2^{\mathrm{a}}$ ed., V. Figueira, Trad.). Porto Alegre: Artmed. (Trabalho original publicado em 2004)

Kishimoto, T. (2000). Solving multiplicative word problems with decimal fractions: The effects of proportional reasoning and metacognition. Em T. Nakahara \& M. Koyama (Orgs.), Proceedings of the $24^{\text {th }}$ Annual Conference of the PME, Vol. 3 (pp. 143-150). Hiroshima: Hiroshima University.
Mekhmandarov. I. (2000). Analysis and synthesis of the Cartesian product by kindergarten children. Em T. Nakahara \& M. Koyama (Orgs.), Proceedings of the $24^{\text {th }}$ Annual Conference of the PME, Vol. 3 (pp.295-301). Hiroshima: Hiroshima University.

Misailadou, C., \& Williams, J. (2003). Measuring children's proportional reasoning, the "tendency" for an additive strategy and the effect of models. Em N. A. Pateman, B. J. Dougherty \& J. Zilliox (Orgs.), Proceedings of $27^{\text {th }}$ Joint Meeting of PME and PMENA, Vol. 3 (pp.293-300). Honolulu: PME/University of Hawaii.

Monteiro, C. (2003). Prospective elementary teachers' misunderstanding in solving ratio and proportion problems. Em N. A. Pateman, B. J. Dougherty \& J. Zilliox (Orgs.), Proceedings of $27^{\text {th }}$. Joint Meeting of PME and PMENA, Vol. 3 (pp.317-323). Honolulu: PME/University of Hawaii.

Moro, M. L. F. \& Soares, M. T. C. (2006a). A aprendizagem de estruturas aditivas elementares - Alunos, professores e pesquisadores como parceiros de uma construção conceitual, Em M. R. F. de Brito (Org.), Solução de problemas e a matemática escolar (pp. 135- 162). Campinas: Alínea Editora,

Moro, M. L. F., \& Soares, M. T. C. (2006b). Níveis de raciocínio combinatório e produto cartesiano na escola fundamental. Educação Matemática Pesquisa, 8, 99-124.

Nunes, T., \& Bryant, P. (1997). Crianças fazendo matemática (S. Costa \& B. V. Dorneles, Trads.). Porto Alegre: Artes Médicas. (Trabalho original publicado em 1996)

Papert, S. (1994). A máquina das crianças: repensando a escola na era da informática (S. Costa, Trad.). Porto Alegre: Artmed.

Park, J. H., \& Nunes T. (2001). The development of the concept of multiplication. Cognitive Development, 16, 763-773.

Pavanello, R. M. (1994). Educação matemática e criatividade. Educação Matemática em Revista, 3, 5-11.

Piaget, J. (1973a). Psicologia e Epistemologia (A. Cretella, Trad.). Rio de Janeiro: Vozes. (Trabalho original publicado em 1970)

Piaget, J. (1973b) Remarques sur l'éducation mathématique. Math École, 58, 1-7.

Sinclair, A. (1990). A notação numérica na criança. Em H. Sinclair (Org.), A produção de notações na criança: linguagem, número, ritmos e melodias (pp. 71-96) (M. L. F. Moro, Trad.) São Paulo: Cortez.

Spinillo, A. G. (1995). Estratégias na resolução de tarefas de proporção por crianças. Em Universidade Federal de Pernambuco e Secretaria de Estado da Educação de Pernambuco (Orgs.), Livro de Resumos da Semana de Estudos em Psicologia da Educação Matemática (pp. 14-18). Recife: UFPE, SEEDPE.

Starepravo, A. R. (1997). Matemática em tempo de transformação. Curitiba: Renascer.

Starepravo, A. R. (2001). A resolução de problemas de estrutura multiplicativa por crianças da $3^{a}$. série do ensino fundamental. Dissertação de Mestrado, Universidade Federal do Paraná, Curitiba.

Taxa, F. de O. S. (2001). Problemas multiplicativos e processos de abstração em crianças na $3^{a}$. série do ensino fundamental. Tese de Doutorado, Universidade de Campinas, Campinas. 
Vergnaud, G. (1983) Multiplicative Structures. Em R. Resh \& M. Landau (Orgs.), Acquisition of mathematics concepts and processes (pp. 127-174). New York: Academic Press.

Vergnaud, G. (1991). El niño, las matemáticas y la realidad. Problemas de la enseñanza de las matemáticas en la escuela primaria. (L. O. Segura, Trad.). México: Trillas. (Trabalho original publicado em 1985)

Recebido em 10.04.07

Primeira decisão editorial em 03.09.08

Versão final em 15.09.08

Aceito em 20.11.08 